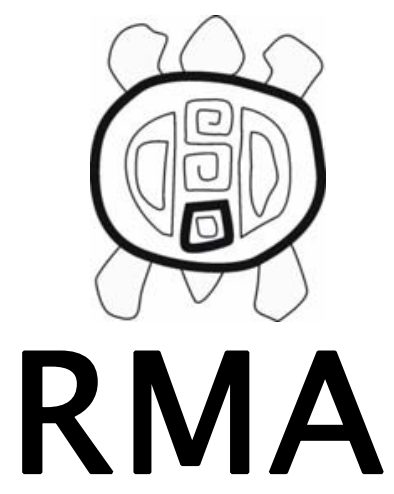

Arqueología

\title{
Análisis e interpretaciones de las representaciones rupestres de Córdoba en publicaciones de fines del s. XIX hasta los ' 80 del s. XX
}

\author{
Graciela Soledad Ochoa \\ Museo de Antropología, Facultad de Filosofía y Humanidades \\ Universidad Nacional de Córdoba \\ gsoledadochoa@hotmail.com
}

\begin{abstract}
Resumen
Las pinturas y los grabados de la provincia de Córdoba han sido estudiados en forma parcial y esporádica. Este artículo intenta ser una síntesis bibliográfica de la literatura, de un largo período que inicia con las primeras publicaciones que comenzaron a circular a fines del siglo XIX, hasta principios de la década de 1980, donde se inicia un nuevo período en las investigaciones marcado por los avances teóricos y metodológicos que se alejan de las descripciones individuales y las comparaciones entre figuras. La síntesis considera los sitios que se priorizaron para su estudio y los criterios mas usuales para su análisis e interpretación.
\end{abstract}

Palabras Clave: representaciones rupestres, literatura científica, semejanzas formales, visión geográfica, homogeneidad cultural

Analysis and interpretation of Córdoba rock art in late XIX through late XX centuries publications.

\section{Abstract}

The paintings and engravings found in the Córdoba province, have been studied partially and sporadically. This article intents to be a bibliographic synthesis of the publications, which starts with the first publications that circulate in the end of the $19^{\text {th }}$ century, until the beginning of the 1980 s', when a new period of investigations sets off marked by theoretical and methodological advances that turns away from individual descriptions and comparisons between figures. The synthesis considers the sites prioritized for their study and the criteria most used for their analysis and interpretation.

Keywords: rock-art representation, scientific literature, similar forms, geographic vision, cultural homogeneity.

\section{Primeros antecedentes}

Muy oportuno sería entonces una exploración, que haciendo tal vez, nuevos hallazgos en la superficie o en las entrañas del terreno, salvara de una destrucción próxima (pues las erosiones continúan) esas páginas de un misterio tan conmovedor...

Leopoldo Lugones, 1903

A finales del siglo XIX y principios del XX se descubren y dan a conocer los primeros sitios arqueológicos con presencia de arte rupestre de la provincia de Córdoba. Son los diarios y revistas científicas provinciales y nacionales, quienes publican las descripciones que viajeros, naturalistas y arqueólogos hacen de las pinturas y grabados de las serranías cordobesas.

Estos primeros trabajos, en su mayoría de carácter descriptivo, contribuyeron al conocimiento de estas manifestaciones. Fueron los que sentaron las bases de las investigaciones que con nuevos enfoques se comenzaron a llevar a cabo en estas últimas décadas. Aquí presentamos una síntesis bibliográfica de las publicaciones de carácter científico que comenzaron a circular a fines del siglo XIX, hasta principios de la década de 1980 del siglo XX donde se inicia un nuevo período en las investigaciones marcada por significativos avances teóricos y 
metodológicos, que van dejando de lado las simples descripciones y comparaciones formales.

La primer referencia que encontramos en una publicación científica es la del naturalista Luis Brackebusch, miembro de la Academia Nacional de Ciencias de Córdoba, quien entre los meses de febrero y abril de 1875 , realiza un viaje por las sierras de Córdoba y San Luis, con el fin de informar sobre el carácter geológico en las cercanías de Sampacho, en las cuales se había comenzado a buscar carbón de piedra. A catorce días de iniciada la expedición, se encontró con el cerro Intihuasi, el cual sitúa a 5 leguas al norte de la localidad de Achiras. Para el geólogo el cerro no sólo tiene importancia desde el punto de vista mineralógico sino también histórico debido a que el mismo representa:

... un punto en que los indios ejecutaban sus ceremonias religiosas, en el cual, más tarde, les servía frecuentemente en sus invasiones como un refugio y lugar señalado. La roca que lo constituye, es un granito muy duro, que se distingue por su estructura globosa ó cascaruda. Por su descomposición se forman huecos redondos llamados «casas de piedra» que han servido á los indios como de escondites y que aun sirven todavía como de casas á algunos vecinos pobres de aquel lugar. En la cima del cerro, poco alto, pero muy áspero, elevándose casi perpendicularmente de las cercanías, se encuentran iguales huecos, pero horizontales, llenos a veces de agua; cerca de ellos se hallan pedazos de pedernales llevados a allí, sin duda por los indios, porque en las cercanías no hay ninguna capa originaria de estas piedras interesantes que son tan importantes en la antropología. Otros signos que indican un culto antiguo de los indios, son diferentes figuras en los huecos pintadas y cinceladas. (Brackebusch 1875: 169-70).

En 1903 el escritor Leopoldo Lugones en un artículo del suplemento ilustrado del diario La Nación, describió algunas de las pinturas que había visto por primera vez mientras realizaba una excursión campestre, el año anterior, en las grutas de Casa del Sol y Cerro Colorado, en el departamento de Río Seco, al norte de la provincia de Córdoba. (Lugones 1903). En la base de la «Casa del Sol» detuvo su paso para describir el primer abrigo donde encontró sólo la figura completa de lo que parecía un gusano; y a pocos metros, en una segunda gruta, unas sesenta figuras en color blanco, negro y rojo. "Pertenecen a esta gruta, [...] representaciones de cuadrúpedos, una especie de lagarto groseramente dibujado, un tigre y un personaje mítico de evidente significación,...»(Lugones 1903).
Saliendo de este pequeño valle llega al Cerro Colorado, siguiendo el curso del arroyo de Los Tártaros. Al pie del cerro encuentra dos grutas, la primera con más de cuarenta figuras y una segunda que llama la atención de Lugones porque contiene más de ciento cincuenta figuras que parecen imitar guerreros alados. El escritor considera que la semejanza de estos dibujos con los Calchaquíes de Carahuasi «les da un alto valor arqueológico pues una identidad comprobada podría indicar o la unidad étnica de tan basta región como la comprendida entre la sierra cordobesa y la frontera boliviana, o la extensión de la conquista incásica.», (Lugones 1903). Alberto Rex González dirá que es a partir del artículo de Lugones que el tema comienza a ser tratado, dando origen a una significativa cantidad de publicaciones dedicadas a esta temática. (González 1940: 333).

Ocho años más tarde Félix Outes publica «Los tiempos prehistóricos y protohistóricos de la provincia de Córdoba» (1911), allí describe la fotografía de un importante friso a orillas del Río Luampampa, cercano a la localidad de Pichanas en el departamento Cruz del Eje.

Sobre una de las márgenes del arroyo de Luampampa que, según entiendo, corre no a mucha distancia de Pichanas (departamento de Cruz del Eje); existe un gran bloque de piedra que ofrece una cara dirigida hacia el poniente, completamente lisa, y sobre el cual aparecen numerosas y complicadas figuras finamente grabadas en la roca. Sería, sin duda, contraproducente describirlas, tal es el conjunto abigarrado que forman, pues se trata, como en otros petroglifos argentinos de líneas irregulares que siguen trayectos muy sinuosos. (Outes 1911:317).

Posteriormente Serrano (1945) señaló un error en la localización de estas manifestaciones, ya que "Outes, en su deseo de ubicar este lugar, lo da como probable a corta distancia de Pichanas. En realidad, Luampampa es la actual Guanaco Pampa, en el departamento San Martín de la provincia de San Luis». (Serrano 1945: 125).

A principios de 1930 Gardner publica en Oxford «Rock Painting of North West Córdoba». Este es el primer investigador que hace un trabajo de relevamiento exhaustivo dedicado sólo al tema rupestre y con carácter puramente científico. EI estudio es sobre las pinturas de los cerros Casa del Sol, Veladero y Cerro Colorado, en el departamento Río Seco; y Agua de la Pilona, en el departamento Cruz del Eje. De Agua de la Pilona dice:

The rock-painting of Agua de la Pilona is situated near place called El Balde, in the department of Cruz del Eje, some three leagues 
to the south-west of the old village of San Marcos. Here we had arranged for a guide to meet us, and setting out in a northerly direction we soon reached the high, wooded banks of the river Quilpo, which, while as yet invisible, made known its presence far below by the noise of the waters rushing over their narrow and rocky bed. On the way up stream our attention was attracted by a chaotic pile of rocks rising from amidst the dense growth of thorny trees and shrubs which clothed the slopes of the left bank, and we were informed by our guide that the place had the reputation of being a salamanca,[...] Agua de la Pilona is a small stream formed by two brooks which emerge from narrow, rocky ravines. At no great distance from their junction, on the right bank of the more southerly of these, is a shelter under an overhanging rock. It faces towards the south-west, and is partly hidden by trees. The floor consists of a ledge of bare rock, a little over two meters in length, and not more than sixty centimeters wide, raised about three meters above the bed of the stream. The height of the shelter at the back is only fifty centimeters, but, owing to the upward slope of the roof, this increases to about eighty centimeters at the mouth. Both ends are closed by large increases to about eighty centimeters at the mouth. Both ends are closed by large blocks of fallen rock. (Gardner 1931: 4-5).

La obra de Gardner fue reconocida por la comunidad científica de la época por su relevamiento minucioso y sistemático, siendo que a través de ella las pinturas rupestres de Córdoba trascendieron las fronteras nacionales.

En «La Antigua Provincia de los Comechingones» (1936) Francisco De Aparicio nos relata el descubrimiento, hecho algunos años antes de su publicación, de una piedra grabada, a orillas del Río Yuspe.

Hace algunos años tuvimos la fortuna de descubrir, [....] en las inmediaciones de Cosquín, [...] la «Piedra marcada de San Buena», [....] Los signos grabados en la roca del Yuspe son rastros de avestruz, de guanaco y de caballo; impresiones de pies humanos, y víboras representadas en distintas formas, desde las que están suavemente onduladas hasta las muy hermosas, cuyo cuerpo se enrosca en amplio espiral y la cabeza se destaca nítidamente. Además, pueden mencionarse una cruz, una figura zoomorfa $y$, luego, algunos signos de interpretación difícil o imposible. (De Aparicio 1936: 403-4).

De Aparicio da importancia a este descubrimiento porque el tipo de representación es distinta a la piedra descripta por Outes en 1911 y a cualquier otro tipo de pintura o grabado que se haya encontrado en la provincia de Córdoba. (De Aparicio 1936:404).

En 1939, Milciades Vignati da a conocer las pinturas encontradas en la localidad de Máscaras en el norte de la provincia. El yacimiento lo ubica a mitad del camino entre la localidad del Tío y Aguada del Monte (Vignati 1939:267). En este trabajo Vignati realiza una descripción muy detallada de cada una de las figuras que encuentra en Máscaras, deteniéndose en forma especial en la representación humana, donde las vestimentas coinciden con las descriptas en las crónicas de la conquista, coincidiendo con las usadas por los aborígenes de Córdoba al momento del ingreso del español a estas tierras (Vignati 1939: 280).

El primer investigador que elabora una síntesis del estado de las investigaciones sobre la temática rupestre en la provincia de Córdoba, es Antonio Serrano en el año 1945. En ésta se describen los tipos de representaciones que caracterizan al Cerro Colorado, Máscaras e Intihuasi; haciendo por primera vez referencia a las pinturas y grabados encontrados en la Sierra de Guasapampa en el departamento Minas. De la sierra de Guasapampa, hace especial referencia al sitio que denomina Charquina, que tiene por característica la presencia de animales como tigres y mulas; y la figura humana realizada en forma esquemática (Serrano 1945).

A principios de la década de 1950 el ingeniero Asbjorn Pedersen innova en el relevamiento del arte rupestre, al utilizar por primera vez la técnica de infrarrojo. Esta es utilizada en las sierras del norte de la provincia de Córdoba en los sitios: Cerro Cóndor Huasi, El Pantanillo, Cerro Casa del Sol (Inti Huasi), Cerro El Veladero, Cerro Colorado, El Desmonte y La Quebrada. Esta técnica permitió a Pedersen reproducir muchos dibujos que no podían ser observados a simple vista, completando los motivos relevados por Gardner veinte años antes.

En 1957 comienzan las investigaciones en el sur provincial de la mano de Hebe Dina Gay quién publica un informe titulado «Las Pictografías del Cerro Intihuasi». Gay sostiene que en el cerro Intihuasi, departamento Río Cuarto, existen distintos tipos de motivos que de acuerdo a su morfología es posible agruparlos en geométricos, diagramas, simbólicos y signos indescifrables, el último grupo lo componen las figuras de animales y humanas, este conjunto es el que predomina sobre el universo de pinturas de Intihuasi (Gay 1957). En una de las grutas encuentra dibujos geométricos formando guardas y en otra un diagrama de gran tamaño es el motivo principal. Llama la atención de la investigadora la presencia de figuras, que interpreta como soles; éste es para ella un elemento significativo, ya que la voz Intihuasi quiere decir casa del sol. En el cerro no es frecuente la representación de la figura humana, 
y cuando está presente, se caracteriza por la falta de indumentaria. «Vemos dos indígenas armados de arco, otro parece con una lanza, el dibujo es rudimentario pero no carente de cierta expresión; en una pequeña concavidad de la roca, se observa un hombre tirando un guanaco.» (Gay 1957). La mayoría de las representaciones corresponden a animales: pumas, un águila con las alas desplegadas, guanacos, avestruces y venados. Estos últimos «sobresalen tanto sobre los demás, que nos hace reflexionar de que sean ellos los mas útiles en la valoración de la altura alcanzada por algunos individuos de esas comunidades primitivas.»(Gay 1957).

Un año después, Alberto Rex González (19561958) realiza el reconocimiento arqueológico en la zona de Copacabana, en el departamento Ischilin, al norte de la provincia de Córdoba, registrando la presencia de un sitio con pinturas y dos con grabados. Las pinturas las encuentra en un abrigo frente al cementerio de Copacabana.

Sobre las paredes del abrigo, [...] existen pintadas en blanco y negro, una serie de pictografías, [...] Es de notar el carácter sumamente esquemático de estas pictografías de Copacabana, pues a excepción de los posibles rastros de avestruz, diseñados de manera bastante realista, las demás figuras son de carácter tan abstracto que es imposible intentar ninguna interpretación. (González 1956-58: 78-79).

A unos seis kilómetros de Copacabana, en un bloque de arenisca que aflora en el puesto conocido como Agua del Molle, localiza el primer grabado.

Los distintos motivos se obtuvieron excavando un delgado canal en la roca, [...] Predominan las figuras geométricas, especialmente los círculos provistos de un punto central, aunque el motivo más saliente lo constituye, por su tamaño, la figura formada por círculos concéntricos, situada en la parte alta del petroglifo. Hacia la derecha existe una figura formada por un rectángulo con dos pequeños puntos simétricos y una serie de líneas verticales sobre la parte alta. (González 1956-1958:1 82-183).

González sostiene que este grabado posee similitudes con el descrito por Félix Outes en 1911. El segundo grabado lo encuentra en el templo de la localidad de Ischilin.

Al realizar nuestra visita a la Iglesia, descubrimos con no poca sorpresa, en uno de sus frentes laterales un petroglifo de indudable factura indígena,[...] Este petroglifo fue trabajado picando la superficie de un bloque poligonal de granito que se usó como sillar en la construcción de la Iglesia, y que presenta en su cara expuesta, una patina mas obscura que el color natural de la roca, de tal manera que el artesano aborigen se contento por hacer desaparecer la delgada capa de la patina, dejando al descubierto el color claro natural del corazón de la piedra, que al contrastar con el resto de la superficie, hace que las figuras dibujadas sean perfectamente visibles. (González 1956-1958:210).

Otra serie de grabados fueron registrados por Juan José Murra en 1965 en la sierra de «Las Lomas Negras» (sierra de Serrezuela, dpto. Cruz del Eje), descubiertos por éste en el año 1963. El hallazgo se realizó cuando se efectuaban observaciones geológicas y recolección de muestras minerales y rocas para el Museo Provincial de Ciencias Naturales Bartolomé Mitre. En este viaje registra un total de doce piedras con grabados, las cuales caracteriza por sus «figuras geométricas muy simples e indescifrables». Sólo una figura es interpretada como la representación del sol (Murra 1965:3-5).

En el año 1968 José Antonio Pérez Gollán publica «Arte Rupestre de Cerro Colorado». Esta retoma algunos de los resultados de excavación llevados a cabo en 1961 por el Instituto de Antropología de la Universidad Nacional de Córdoba, bajo la dirección de González; que habían sido dados a conocer en la revista Gacetita de 1963 y 1965. Pérez Gollán sostiene que las pinturas del Cerro Colorado sólo pueden ser entendidas dentro del contexto cultural de los pueblos que habitaron las serranías.

A más de 30 años de las referencias que Serrano hiciera sobre algunos de los motivos de los sitios de La Playa y la Sierra de Guasapampa, Alberto Romero (Romero et al. 1973) y su equipo dan a conocer los resultados preliminares de los relevamientos que desde fines de la década de 1960 llevaban a cabo en los sitios rupestres de La Playa en el departamento Minas. «En la Playa, en la amplia zona prospectada y distribuidos en varios sitios cercanos entre si, se descubrieron más de sesenta lugares con manifestaciones de arte aborígen» (Romero et al. 1973). Entre el año 1972 a 1978 junto a Alejandra Uanini, dan a conocer y describen dos sitios con grabados en Ampiza. Estos forman parte del yacimiento arqueológico de Aguas de Ramón, ubicado en la Sierra de Guasapampa, al oeste provincial. Al primer sitio descripto lo caracterizan por la diversidad en los motivos «predominando en ellos el diseño curvilíneo y las figuras resultantes de la combinación de círculos con puntos y apéndices lineales» (Romero y Uanini 1978). Estas figuras son interpretadas como "representaciones humanas muy esquemáticas, en las cuales se ha dado mas valor a ciertos rasgos, tales como la 
cabeza y sus adornos» (Romero y Uanini 1978). También se hace mención a una roca ubicada al sur del anterior alero, en cuya superficie se encuentran grabados motivos zoomorfos; y cercano a este, a un bloque con motivos geométricos, que se encuentra caído sobre el cauce del río. El segundo sitio es ubicado al sur de la población de Aguas de Ramón, cercano al cementerio. El motivo es un «grabado compuesto por rombos unidos por el vértice (con círculos internos) y enmarcados por líneas quebradas» (Romero y Uanini 1978: 25).

Dos nuevos conjuntos de pinturas son descriptos por José Cocilovo y Alberto Marcelino en el Primer Congreso de Arqueología Argentina del año 1970. El primero es en el Cerro Puntudo ubicado en el departamento Sobremonte. Entre los motivos representados aparece la figura del felino acosado por los perros y la humana con ornamento cefálico de plumas sosteniendo un arco propulsor. El segundo conjunto corresponde a Casa Pintada en el departamento Río Cuarto. Aquí aparece el jinete a caballo, los perros y la figura del lagarto; al igual que en el Cerro Puntudo hay presencia de figuras geométricas pero en menor proporción. (Cocilovo y Marcelino 1975).

Las publicaciones hasta aquí tratadas se caracterizaron por las descripciones individuales y las comparaciones formales. Sin embargo y como veremos mas adelante estuvo presente el intento de organizar los datos bajo esquemas de sistematización espacial y estilísticas, y darles un sentido mediante diferentes interpretaciones. Estos primeros trabajos sentaron las bases de nuevas investigaciones con criterios diferentes, que centraron su análisis en el contexto arqueológico de las representaciones, la distribución espacial de los sitios y el estado de conservación y factores de deterioro que los afectan.

\section{Esquemas de sistematización espacial y estilística}

Las investigaciones dedicadas a las representaciones rupestres de las sierras cordobesas se han caracterizado por tomar como criterio de análisis la división por región geográfica. El primer estudio de este tipo lo encontramos en «Los Comechingones» de Antonio Serrano (1945). Éste investigador sostuvo que las sierras de la provincia de Córdoba presentan particularidades locales que posibilita su estudio por zonas geográficas.

«En primer lugar debemos destacar la zona del Cerro Colorado (históricamente ubicada en la región de los sanavirones). Su caracterización estaría dada por las figuras de cazadores emplumados, las figuras humanas en cadena, el puntillismo en la representación del felino» (Serrano 1945:137). La segunda zona la ubica en «el noroeste de la provincia con figuras humanas de frente, descriptivas, $y$ dibujos con escalonados de origen eskeiomórfico.»(Serrano 1945:137).

Las similitudes y diferencias en la representación hicieron suponer a Serrano una posible vinculación entre las pinturas del norte de la provincia (Cerro Colorado) con las de Patagonia y las del noroeste (Máscaras) con las pinturas de la provincia de La Rioja y sur de Santiago del Estero. El resto del territorio cordobés carecería de las características diferenciales que tienen las dos localidades mencionadas. Sin embargo Serrano consideró la posibilidad de otra región, que ubica en el occidente provincial, cuyo tipo de representación se caracterizaría por la presencia de «animales pintados sus contornos de gruesos trazos (rojos en La Playa o Guasapampa) y rellenado su interior de blanco» (Serrano 1945:138). Corresponderían a esta misma modalidad algunos dibujos de tipo geométrico del Cerro de San José y Colorado (Serrano 1945).

Romero, Uanini y Arguello unifican la zona norte y noroeste identificada por Serrano, sumando los sitios de Agua de Ramón al sector occidental.

Dos zonas se destacan por la cantidad de repositorios de Arte Rupestre que en ellas se encuentran. Una es la zona del norte de la provincia, en donde se hallan ubicados Cerro Colorado y otros sitios cercanos al mismo. La otra corresponde al oeste, principalmente al Departamento Minas, donde se encuentran La Playa y Agua de Ramón (Romero et al. 1973).

En el mismo trabajo se mencionan una serie de sitios que se encuentran aislados: Casa Pintada y Cerro Inthuasi (Dpto. Río Cuarto), Lomas Negras y La Higuera (Dpto. Cruz del Eje), Cosquín (Dpto. Punilla), Cerro Puntudo (Dpto. Sobremonte) y Mina Clavero (Dpto. San Alberto).

Según Alberto Rex González habría que aplicar un criterio geográfico para Córdoba, al ser todavía escasas las publicaciones científicas en relación con la cantidad de sitios posibles sin relevar. Esta razón lo lleva a considerar prematuro cualquier intento de síntesis o sistematización espacial o estilística (González 1977:84). Siguiendo este criterio amplió en 1977 las zonas de distribución geográfica, dividiendo a las Sierras Centrales en cuatro sectores bien diferenciados: Norte, Sud, Centro oeste y Serranía puntana. El sector Norte cercano a los límites con Santiago del Estero, abarcando desde Pozo del Tigre hasta el Cerro Colorado, cuenta con dos importantes localidades arqueológicas: Cerro Colorado y Máscaras es el «más interesante tanto por la diversidad de sus estilos y cantidad de cavernas con arte rupestre, 
como por la calidad artística de sus imágenes.» (González 1977:84). El sector Sud situado en el departamento Río Cuarto al sur de la provincia de Córdoba, tiene como localidad arqueológica más importante al Cerro Intihuasi.

... desde el punto de vista estilístico y técnico las pictografías de Intihuasi publicadas hasta hoy, son mucho más simples que las de Cerro Colorado. Predominan netamente las figuras animales muy sencillas, aisladas o mas frecuentemente formando escenas de conjunto; faltan las figuras animales elaboradas: Ios cóndores con las alas abiertas o el quitilipi (lechucita lugareña) del sector N. (González 1977:94).

Algunos animales y figuras humanas «sencillas» portando arco y flecha, considera similares, por su estilo y aspecto formal, a algunas figuras que se encuentran en el sector Norte. El tercer sector, en el departamento Minas, es un valle formado por las sierras de Guasapampa y las estribaciones de la Sierra de Pocho y Ciénaga del Coro. Las localidades arqueológicas más relevantes son La Playa y Agua de Ramón. «Parece que en este sector, tampoco existen los guerreros emplumados y polícromos característicos de «la escuela» de Cerro Colorado. En cambio hay afinidad entre los grupos de figuras zoomorfas de ambos lugares.» (González 1977:94). El último sector comprende las serranías de la provincia de San Luis. Las localidades arqueológicas más importantes son: Intihuasi, Sololosta, La Ciénaga, Cuchi Corral, Agua Linda, El Puesto, General Urquiza, Quebrada de Los Bayos, San Felipe, Paso del Rey y el Saladillo.

En general San Luis pareciera tener un arte rupestre con un mayor predominio de elementos geométricos y abstractos. Entre los primeros hay mucho en común con la serranía cordobesa pero también hay notables diferencias. Faltan aquí no sólo los guerreros emplumados, sino también las imágenes complejas de animales característicos del estilo del sector $N$ y las figuras humanas con rasgos anatómicos faciales. (González 1977:96).

El arte rupestre de esta región queda caracterizado por este autor como muy pobre en cuanto a logros artísticos, técnica y combinación de colores. González considera que a medida que se desciende desde el norte al sur provincial, las representaciones van sufriendo un progresivo empobrecimiento en cuanto al tipo de motivos y técnicas empleadas (González 1977:94).

Berberián y Nielsen se apartan de este criterio cuando agrupan por morfología pinturas provenientes de diferentes sitios de la provincia de Córdoba, pero sin llegar a realizar un análisis de tipo estilístico. El análisis comparativo de los motivos les permite formular a modo de hipótesis, la existencia de dos grupos con tendencias particulares en cuanto a la forma de representación. (Berberián y Nielsen 1985:27). El primer grupo lo forman las pinturas de Máscaras, Cerro Puntudo y Cerro Colorado (Dpto. Sobremonte), La Aguada (Dpto. Tulumba), Intihuasi y Casa Pintada (Dpto. Río Cuarto). Caracterizan a este grupo «la abundancia de motivos figurativos de carácter naturalista, destacándose la figura humana con indicación de diversos detalles.» El segundo grupo está integrado por las pinturas de La Playa (Dpto. Minas), La Playa (Dpto. Punilla), Suana (Dpto.Tulumba), Copacabana (Dpto.Ischilin), Cerro San José (Dpto. San Alberto) y Agua de la Pilona (Dpto. Cruz del Eje). En este grupo sobresale «el esquematismo en las representaciones de carácter figurativo.» (Berberián y Nielsen 1985:27). Los autores advierten que:

Las pinturas del primer grupo se encuentran fundamentalmente en la región de lengua sanavirón y de dialecto camiare mientras que las del segundo conjunto, se presentan principalmente en el sector henia, donde en algunos casos como en el departamento Minas, no se ha registrado ni un vocablo de origen sanavirón. (Berberián y Nielsen 1985: 28).

Trabajos recientes, como de Ana María Rochietti no acuerda con el criterio geográfico, por considerar que esta forma de organización de los datos es útil para los trabajos de síntesis, pero no llegan a «expresar la heterogeneidad de los fenómenos rupestres que contiene ni el significado real de la distribución espacial de los sitios.» (Rochietti 2000:127).

\section{Las interpretaciones}

Uno de los grandes interrogantes al que todos los investigadores han intentado dar respuesta, es sobre el posible significado que han tenido las pinturas y grabados rupestres para los pueblos indígenas que las realizaron. Interrogante al que se ha dado diferentes respuestas, desde la interpretación que las considera obras de arte que fueron creadas con el único fin de embellecer un lugar, en un momento histórico donde los recursos eran abundantes y las representaciones eran el fruto del ocio, pasando por interpretaciones de tipo mágico religiosas, hasta las más recientes donde el significado de estas, en muchos casos, ya ni siquiera es planteado.

Consideramos que en Córdoba la constante ha sido el enfoque que relaciona lo rupestre con el ámbito de lo mágico y lo ritual. Esta 
formulación tuvo origen en la literatura antropológica de fines de siglo XIX, y fue aplicada estrictamente a la interpretación del arte paleolítico europeo. A través de los ritos mágicos el hombre obtenía el control del medio, y era a través de la representación como el artista obtenía una influencia determinante sobre aquello que se había representado. El arte, [...] se encontraba así cimentado en lo que se le suponía a un grupo de individuos prehistóricos con necesidades básicas y casi «únicas»: la caza y la reproducción.» (Pascua Turrión 2005). A través de éstos el hombre obtenía el control del medio que lo rodeaba, por medio de la representación el artista obtenía total influencia sobre aquello que él había representado.

Gardner dedica un capítulo en «Rock-Painting of North-West Córdoba» a los posibles significados de las rocas pintadas y a considerar la aplicación de estos modelos de análisis del Paleolítico europeo, por proveer elementos que ayuden a la comparación con las pinturas de las serranías cordobesas. Este tipo de análisis lleva a Gardner a descartar que todas las imágenes tuvieran un sentido estrictamente estético o mágico, dando lugar a la variabilidad de motivos que originaron las pinturas.

Concerning the rock-painting of northwest Córdoba in general, one thing can be said, without hesitation: they were not done merely to pass the time. Some of them are high up, out of reach from the ground, or in positions very difficult of access, others are on the under side of ledges of rock close to the floor of the shelters; and it hardly conceivable that the Indian would have undergone the great labour and discomfort that the painting of many of the figures must have entailed, merely because he had nothing else to do. Some other explanation must be sought, and one might be found in artistic instinct, expressing itself in the decoration of the home, or even brought out by a spirit of rivalry. (Gardner 1931: 126).

Aproximaciones de tipo mágico-religiosas la encontramos en trabajos como los de Asbjorn Pedersen quien sostuvo que parar poder comprender el significado del arte rupestre es necesario señalar que:

... obedecían exclusivamente a una ideología mágico-religiosa practicada por el hombre $y$ ejecutada conforme a conjuros $y$ ceremonias para lograr concesiones sobrenaturales especiales, [...] Por tal motivo, las creaciones rupestres, aparte de la significación artística que pueda asignárseles son esencialmente expresiones de culto ritual. (Pedersen 1960:9).
Hebe Dina Gay expresa conceptos similares para las pinturas de Intihuasi «no es de dudar que se encuentra en ellas ese algo de común del sentir del hombre primitivo, trasluciendo su adoración a la naturaleza y el afán de superarla con ritos mágicos.», (Gay 1957:1). Las pinturas de Intihuasi son un «documento de la mágica religión de la vida de estos pueblos; materia para el estudio del choque del hombre primitivo contra la naturaleza.» (Gay 1957:1). Los motivos geométricos quedan al margen de esta explicación, por ser considerados simplemente un elemento decorativo.

Serrano sostiene sobre algunas representaciones antropomorfas de Cerro Colorado que «los personajes enmascarados que aparecen en las escenas de caza, [...] son seguramente hechiceros que intervenían con sus medios mágicos para el mejor éxito de la cacería.» (Serrano 1945: 335). Para este mismo lugar González considera que las pinturas pueden haber cumplido distintas funciones, no siendo el producto de un simple pasatiempo, ni pura creación estética, todas debieron tener significados precisos, cumpliendo con funciones variadas. No descarta que muchos abrigos con motivos geométricos, pudieran haberse utilizado para realizar «ceremonias especiales ligadas con los incomprensibles signos.» Señala que no se puede negar que muchas escenas representan hechos históricos vividos por los grupos que realizaron los dibujos. (González 1977:89).

Hay un hecho incontrovertible: algunas de las escenas representan a todas luces, un hecho histórico, la entrada y avance de la conquista en Córdoba. Marca un hito trascendente en la historia indígena, a la par que la vista de hombres blancos, provistos de armas relucientes, acompañados de extrañas bestias y feroces perros que los naturales contemplaban por primera vez, marcan el comienzo de la declinación de la cultura autóctona y con ella la desaparición de los primeros indios. De la misma manera que esa escena representa con claridad un hecho histórico conocido, puede suponerse que las otras en que aparecen grupos de guerreros enfrentados en plena lucha, también fueron acontecimientos vividos por las tribus. (González 1965: 25).

Hay otra serie de escenas donde:

El shaman parece ser un hombre que viste un largo manto, quizás de lana; cae a los costados, suelto y amplio, dando una imagen muy distinta a la de los guerreros. En un caso, el shaman parece ser el blanco de dos sujetos armados que se aprestan a dispararles sus 
flechas; escena extraña, quizá representa la represalia por la acción mágica fallida o la venganza de la magia cumplida. (González 1977: 88).

Romero coincide con González en señalar que la función de las pinturas no pudo ser exclusivamente brindar goce estético, si se consideran que "Las formas más antiguas conocidas, las artes plásticas y graficas del paleolítico, en las cuales vemos la íntima relación que tienen estas expresiones, tanto con las actividades económicas como con las formas cúlticas y mágicas.» (Romero et al. 1978)

Lo mágico-religioso, en algunos casos está unido a la idea de santuario, considerando a las cuevas y aleros como lugar sagrado donde alguna vez fue escenario de rituales mágicos.

Uno de los tantos reparos del cerro Intiguasi (Cerro Colorado) fueron cavados morteros fijos, en la roca de asperón de la formación, pero de otra forma donde no cabe equiparación, construidos a alto nivel, para comodidad del hombre nos da a suponer fueron reservados para finalidades rituales de tener en cuenta por otras razones, la denominación e importancia del lugar donde todo propende, presionado por el ambiente, no considerarlo destinado a las operaciones corrientes de moliendas. Al amparo de las intemperies, donde todo nos lleva a meditar sobre su significado, en su esencia desconocida, pero debemos suponerlo ideológico, donde bóvedas y paredes, cuajados de pictografías casi todas pequeñas, acumuladas por el hombre en el transcurso de los años, a cual más interesante de figuras veristas y estilizaciones enigmáticas las más, donde existe material para desarrollar un vasto programa interpretativo, de indianos que dejaron en esa forma de huellas de sus sentimientos en ese lugar. Parte de esas figuras las encontramos miniadas en huesos, rocas, alfarerías, moluscos en San Roque ocupan también su lugar en ese templo agreste de los gentiles. (Magnin 1941:198).

Las interpretaciones de tipo mágico religioso han estado presentes en la mayoría de las investigaciones que han tratado sobre las pinturas y los grabados rupestres, no ha sido una visión exclusiva de los trabajos de divulgación sobre el tema. Esta interpretación estuvo vigente en la mayoría de los trabajos de carácter científico; que sin mostrar una clara visión de su significado, utilizaron en forma constante e indistinta conceptos como el de magia y religión. Consideramos que la mayoría de las interpretaciones que los investigadores dieron para entender las representaciones de la provincia Córdoba, respondieron a los mismos paradigmas explicativos que giraban en ese momento en torno al arte paleolítico.

\section{Consideraciones finales}

Hemos tratado la literatura científica que fue publicada desde fines del siglo XIX, hasta principios de la década de 1980, referida a lo rupestre en Córdoba. No desconocemos la infinidad de artículos periodísticos que han tratado el tema en especial cada vez que se «descubría» un nuevo conjunto; aquí sólo hemos tomado el artículo escrito por Leopoldo Lugones porque marca el inicio de una larga serie de trabajos, periodísticos y científicos, dedicados a las pinturas y grabados rupestres de las serranías cordobesas.

Desde el informe de Brackebusch sobre Intihuasi (1875), y en especial desde la publicación de Lugones sobre el Cerro Colorado (1903), han sido frecuentes las publicaciones referidas al arte rupestre de la provincia de Córdoba, pero deberemos esperar hasta la década de 1930 para que estudios más sistemáticos de registro fomentados por investigadores como Gardner (1931) y Vignati (1939), entre otros, den al arte rupestre un lugar importante dentro de la arqueología. En general esas investigaciones, de fines del S. XIX y principios del S. XX, basaron su análisis en documentos históricos sin dar mayor peso a las asociaciones contextuales.

La idea de contexto adquiere relevancia en la década de 1960, con la publicación de Pérez Gollán sobre el Cerro Colorado. Los motivos comienzan a ser analizados no sólo a luz de la documentación de la época de la conquista, se los relaciona con las excavaciones llevadas a cabo en los distintos sitios arqueológicos de Córdoba. Los trabajos que siguieron al de Pérez Gollán (Romero et al. 1973, Berberián y Nielsen 1985, González 1977) buscaron situar los motivos dentro del contexto arqueológico de la provincia.

Desde aquellos primeros artículos la mayoría de las investigaciones y publicaciones sobre ésta temática ha tomado como parámetro, y ha tratado en forma casi exclusiva las pinturas del Cerro Colorado (Gardner 1931, De Aparicio 1936, Serrano 1945, González 1940, 1956, 1977, Pérez Gollán 1968). La importancia que siempre se ha dado a este conjunto de manifestaciones rupestres en relación con otros, creemos que se debe a una valoración estética de sus representaciones, y porque es uno de los lugares con mayor cantidad de pinturas de la provincia. En palabras de De Aparicio: el «mas rico tesoro que los aborígenes del País -y quizás del continente- hayan dejado en pinturas rupestres.» (De Aparicio 1936:402), pese a lo cual Berberián y Nielsen sostienen que:

«la condición en la que se encuentran los yacimientos en todos los departamentos 
provinciales, a excepción del Cerro Colorado, es poco menos que precaria o nula en lo referente no sólo las obras de especialización científica dedicadas a este tema, sino también a trabajos de relevamientos en campaña,... (Berberián y Nielsen 1985:18).

Como señalábamos, en este período, el arte rupestre de la provincia de Córdoba ha sido estudiado en forma parcial y esporádica lo que impidió una visión integral de la región central. El criterio de la división geográfica es la que primó en las investigaciones, caracterizado por la agrupación de sitios, pero también por las similitudes estilísticas presentes en cada área. Los sitios ubicados fuera de éstas quedaron señalados como sitios aislados. (Romero et al. 1973). A pesar que Berberián y Nielsen se apartan de este modelo para comparar motivos de distintos sitios, sin pretender un análisis de tipo estilístico, realizan comparaciones formales que aíslan los motivos de su contexto histórico y cultural, (Berberián y Nielsen 1985). Consideramos que ambas maneras de agrupamiento: la visión geográfica y de semejanzas formales, suponen una cultura homogénea para los indígenas que habitaron las serranías. Si bien se reconoce que al momento de la conquista las sierras estaban pobladas por varias etnías se sostiene que «los estudios arqueológicos [...] indican que hubo una uniformidad cultural bastante grande» (González 1977: 79) donde sus expresiones artísticas son el reflejo de la situación periférica e intermedia entre las culturas avanzadas del Noroeste y los pueblos nómadas que habitaron la Patagonia. (González 1977:79).

Pensamos que todo el periodo analizado esta atravesado por el supuesto de una unidad cultural, donde los diferentes grupos que poblaron las sierras han sido poseedores de una forma de vida semejante, en donde las pinturas y grabados rupestres son la máxima expresión de la vida espiritual de estos pueblos.

Córdoba, 8 de septiembre de 2008

\section{Bibliografía}

Berberián, E y Nielsen, A. 1985. El Arte Rupestre de la Región Serrana de la Pcia. de Córdoba (República Argentina). Revista Comenchingonia, N5. pp.17-30.

Brackebusch, L. 1875. Informe sobre un viaje geológico, hecho en el verano del año 1875, por las Sierras de Córdoba y de San Luis. Boletín de la Academia de Ciencias Exactas de Córdoba. Tomo II. pp. 167-216.

Cocilovo, J., A. Marcelino. 1975. Dos nuevos grupos pictográficos de la provincia de Córdoba. Actas y Trabajos del Primer Congreso de
Arqueología Argentina. Museo Histórico Provincial «Dr. Julio Marc». pp. 271-285. Buenos Aires

De Aparicio, F. 1936. La Antigua Provincia de los Comenchimgones. De la historia de la Nación Argentina. Junta de Historia y Numismática Americana. Tomo I, pp. 289-427. Buenos Aires.

Gay, H. 1957. Pictografías del Cerro Intihuasi. Notas del Museo de Ciencias Naturales «Bartolomé Mitre». pp. 1-7.

Gardner, G. 1931. Rock-Painting of North West Córdoba. Oxford. pp.1-147.

González, A. 1940. Las pinturas rupestres del Cerro Colorado. Revista Geográfica Americana. Año VIII, vol. XIV. pp. 333-34.

González, A. 1956/58. Reconocimiento arqueológico de la zona de Copacabana (Córdoba). Separata de la Revista do Museo Paulista, Nova Serie. Volumen X. pp. 174-212. Sao Paulo.

González, A. 1965. Las pinturas indígenas del Cerro Colorado. Revista Gacetita 79, Año VIII, pp. 25-26.

González, A. 1977. Arte precolombino de la Argentina. Filmediciones Valero, pp. 79-96. Buenos Aires.

Lugones, L. 26 de marzo de 1903. Las grutas pintadas del Cerro Colorado. Suplemento ilustrado, Diario La Nación.

Magnin, J. 1941. «Notas Indianas regionales de la región central de Córdoba del Tucumán». Congreso de Historia Argentina del Norte y Centro. Arqueología, Lingüística y Folclore, pp. 198.

Murra, J. 1965. Sobre el hallazgo de petroglifos en las Sierras de Lomas Negras. Notas del Museo de Ciencias Naturales Bartolomé Mitre, pp. 1-5.

Pascua Turriòn, J. 2005. El Arte Paleolítico: Historia de la investigación, escuelas interpretativas, y problemática sobre su significado. Arqueoweb. http://www.ucm.es/info/arqueoweb/numero7_2/ conjunto7_2.htm. (Última consulta: 1/09/2008).

Pedersen, A. 1953-1954. El infrarrojo y su aplicación en la investigación de las pinturas rupestres. Runa. Volumen VI, pp 216-219.

Pedersen, A. 1960. Pinturas Rupestres de la Argentina. Ministerio de Educación y Justicia. Dirección General de Cultura, pp. 1-9. Buenos Aires.

Pérez Gollán, J. 1968. Arte Rupestre de Cerro Colorado, pp. 5-21. Filmediciones Valero, Buenos Aires. 
Outes, F. 1911. Los tiempos prehistóricos y protohistóricos en la provincia de Córdoba. Revista del Museo de La Plata, VIII, pp 317.

Rocchietti, A. 2000. Arte Rupestre de la Sierra de Comechingones (Cba). Síntesis Regional. «En: Arte en las Rocas». Editado por: Podestá Maria y De Hoyos Maria, pp.127. Buenos Aires.

Romero, C., E. Arguello y A. Uanini. 1973. El arte Rupestre en Córdoba. Revista Proyecciones, Nro.8, Ika Renault.
Romero, C., A. Uanini. 1978. Los grabados rupestres del Sitio Ampiza 1 (Aguas de Ramón. Dpto Minas. Pcia de Córdoba). Revista del Instituto de Antropología, Tomo VI, pp. 111-133.

Serrano, A. 1945. Los Comenchingones. Serie aborígenes argentinos VI. Instituto de Arqueología, Lingüística y Folclore, pp. 125-138, UNC, Córdoba.

Vignati, M. 1939. El arte parietal indígena en Mascaras. Al norte de la provincia de Córdoba. Notas del Museo de La Plata, Tomo IV, № 14, pp. 264-284. 